\title{
O LUGAR DA CRIANÇA NA PESQUISA: QUESTÕES TEÓRICO-METODOLÓGICAS E ÉTICAS
}

\author{
THE PLACE OF THE CHILD IN THE RESEARCH: THEORETICAL- \\ -METHODOLOGICAL AND ETHICAL ISSUES
}

\section{EL LUGAR DE LA INFANCIA EN LA INVESTIGACIÓN: CUESTIONES TEÓRICO-METODOLÓGICAS Y ÉTICAS}

\author{
Marta Regina Brostolin ${ }^{1}$ \\ ${ }^{1}$ Universidade Católica Dom Bosco (UCDB), Campo Grande/MS - Brasil
}

\begin{abstract}
Resumo A pesquisa com crianças a partir da Sociologia da Infância surge como uma nova vertente de estudos científicos. De forma tímida, inicialmente, vem ao longo dos anos sendo mais utilizada por pesquisadores da infância garantindo às crianças o direito de expressão e audição. Esse novo campo teórico-empírico transforma as crianças de objetos em sujeitos participantes da pesquisa. Nesse contexto se insere a problemática subjacente a este texto que procura refletir sobre qual o lugar da criança na pesquisa, as questões teórico-metodológicas envolvidas e que cuidados éticos são necessários no desenvolvimento da investigação. Conhecer a criança e adentrar seu mundo por meio da pesquisa participativa exige a criação de múltiplos olhares acerca do contexto e a respeito do modo como delineia suas ações. Implica na criação de estratégias metodológicas que lhe permita diferentes modos de expressão, audição e movimentos, sendo tarefa do pesquisador adulto tornar audíveis e visíveis as ações das crianças durante a investigação. A pesquisa e o desenho pelo qual é constituída deverá criar condições para que crianças e adultos possam, a partir de diferentes linguagens, visibilizar as ações e lhes dar sentido. Além das questões teórico-metodológicas, deve-se também ter muita atenção à ética em respeito à criança e cuidados com seu bem-estar. Trata-se de considerar e dar à criança seu lugar como participante e parceira no processo de investigação, partilhando um espaço intersubjetivo e inter-relacional de forma efetiva e ética.
\end{abstract}

Palavras chave: Criança; Direitos da criança; Pesquisa participativa; Sociologia DA INFÂNCIA. 
ABSTRaCr Research with children emerged from the Sociology of Childhood as a new strand of scientific studies. In a timid way, initially, it comes over the years being more used by researchers of the childhood guaranteeing the children the right of expression and hearing. This new theoretical-empirical field transforms the children of objects into the subjects of the research. In this context, the underlying problem of this text is inserted, which seeks to reflect on the place of the child in the research, the theoretical and methodological issues involved and what ethical care is needed in the development of research. Knowing the child and entering the world through participatory research requires the creation of multiple perspectives on the context and how it delineates its actions. It implies in the creation of methodological strategies that allow different ways of expression, hearing and movements, being the task of the adult researcher to make audible and visible to the actions of the children during the investigation. The research and the drawing by which it is constituted should create conditions so that children and adults can, from different languages, visualize the actions and give them meaning. In addition to the theoretical-methodological issues, one should also pay close attention to ethics regarding the child and care for his well-being. It is a question of considering and giving the child his place as participant and partner in the research process, sharing an intersubjective and inter-relational space in an effective and ethical way.

Keywords: Child; Rights of the child; Participatory research; Sociology of ChILDHOOD.

RESUMEN La investigación con los(as) niños(as) surgió a partir de la Sociología de la Infancia como una nueva vertiente de estudios científicos. Aunque de forma tímida, inicialmente, a lo largo de los años está siendo más utilizada por investigadores de la infancia garantizándole a los(as) niños(as) el derecho de expresarse y de ser escuchados. Este nuevo campo teórico-empírico transforma los(as) niños(as) de objetos en sujetos participantes de la investigación. En ese contexto se sitúa la problemática subyacente a este texto que procura reflexionar sobre el lugar de los(as) niños(as) en la investigación, las cuestiones teórico-metodológicas y los cuidados éticos que son necesarios en el desarrollo de la investigación. Conocer a los(as) niños(as) y adentrar en su mundo por medio de la investigación participativa exige la creación de múltiples puntos de vista sobre el contexto y sobre la manera de delinear sus acciones. Implica la creación de estrategias metodológicas que permitan diferentes modos de expresión, audición y movimientos, y es tarea del investigador adulto hacer audibles y visibles las acciones de los niños durante el trabajo. La investigación deberá crear condiciones para que niños y adultos puedan, a partir de diferentes lenguajes, visibilizar las acciones y darles sentido. Además de las cuestiones teórico-metodológicas, también hay que tener mucho cuidado con la ética, con respeto a los(as) niños(as) y cuidar de su bienestar. Se trata de considerar y darle al(a la) niño(a) su lugar como participante en el proceso de investigación, compartiendo un espacio intersubjetivo y de interrelación de forma efectiva y ética.

Palabras-Clave: Infancia; Derechos del(de la) niño(a); InVestigación Participativa; SOCIOLOGÍA DE LA INFANCIA. 


\section{Algumas PalaVras inTrodutórias}

A atual conjuntura da infância tornou-se um tema presente em muitas agendas sociais e políticas mundiais, mais concretamente nos países centrais do que nos países periféricos, expressando o discurso legítimo da importância que a infância assume como grupo social na contemporaneidade.

Entre as diversas problemáticas que envolvem a infância que vão de contextos de risco, à privação de necessidades mais básicas, ou seja, o cerceamento de seus direitos de proteção, de provisão e de participação como cidadão atuante na sociedade, este texto se propõe a refletir sobre a participação da criança na pesquisa, consolidando assim o registro de sua voz e ação na tentativa de construir mundos sociais e culturais mais genuínos e participativos (FERNANDES, 2009).

A participação da criança na pesquisa como sujeito a partir da Sociologia da Infância surge como uma nova vertente de estudos científicos, que têm por pressupostos básicos a ação e voz da criança e a compreende como ator social, entendendo também a infância como uma categoria geracional socialmente construída. De forma tímida, inicialmente, a pesquisa deixa de ser sobre as crianças para ao longo dos últimos anos ser desenvolvida com a criança e, dessa forma, ser mais utilizada por pesquisadores da infância, garantindo assim às crianças o direito de expressão, audição e movimentos. Esse novo campo teórico-empírico transforma as crianças de objetos em sujeitos participantes da pesquisa.

O processo de escuta das crianças, de modo especial nas pesquisas, construiu-se historicamente. Pode-se dizer que no Brasil essa prática está presente desde 1990, quando também surgiu com mais intensidade no país a Sociologia da Infância. A partir de então, cada vez mais as crianças têm tido a oportunidade de se expressarem nas pesquisas. Essa realidade tem se estendido também além da educação infantil para outras áreas de conhecimento, como a psicologia, a saúde, a antropologia e o campo jurídico, evidenciando que cada vez mais as crianças têm sido respeitadas e valorizadas como sujeitos ativos participantes da sociedade (FORMOSINHO, 2008).

Revendo brevemente esse percurso, de acordo com Belloni (2009), a infância foi por muito tempo negligenciada nas pesquisas, sendo apenas evidenciada quando os grupos minoritários e excluídos da sociedade passam a aparecer com mais amplitude nas pesquisas, como é o caso da infância e da mulher. Esclarece a autora que:

\footnotetext{
Somente ao final do século XX os estudos sociológicos chegaram a um novo patamar, descobrindo a infância como categoria e objeto de estudo pleno e relevante, passando a considerar as crianças atores importantes nas interações sociais, e tentando construir novos paradigmas de compreensão desses fatos sociais, a partir do questionamento das oposições e dicotomias da modernidade e dos conceitos clássicos de socialização (BELLONI, 2009, p. 122).
}

No cenário descrito por Belloni (2009), a Sociologia da Infância se propõe a discutir o extenso corpo de conhecimentos produzido, ao longo do século XX, sobre o desenvolvimento e a socialização da criança. As teorias tradicionais ignoram a análise sociológica da infância sobre si mesma, subordinando-a à análise de instituições sociais como a família e a 
escola, ocultando seus mundos sociais e culturais, mostrando uma imagem de infância subjugada pelas normas sociais e reprodutora dessas mesmas normas (FERNANDES, 2009).

Segundo Sarmento (2016), a criança foi compreendida por muito tempo a partir de duas ideias básicas, isto é, que precisa ser educada por não ter uma cultura própria e, nesse sentido, são criadas as instituições educativas e, por último, também não apresenta uma moralidade própria, o que significa que precisa ser socializada dentro dos valores e normas da sociedade vigente.

Constitui-se então a normatividade infantil pela modernidade que compreende a criança a partir da sua negatividade, ou seja, daquilo que ela não é e ou daquilo que não tem em detrimento daquilo que ela pode, faz. Uma infância separada do adulto que precisa ser educada. A infância da modernidade "é uma infância pensada como geração do devir, em transformação, no sentido de futuro” (SARMENTO, 2016, p. 8).

Em contraposição e rompendo com essa concepção da modernidade, a Sociologia da Infância intenta um novo olhar para a criança a partir "do que ela é, do que sabe, do que pode, das suas competências, das suas formas de construir cultura, do modo como elabora sistemas ideológicos, não necessariamente coincidentes com o dos adultos" (SARMENTO, 2016 , p. 8). Um olhar que acentue a ação social da criança e sua participação no processo de socialização, que considere as leituras que as crianças fazem de seus cotidianos, dos problemas e necessidades enfrentadas e possibilite a elas ocupar lugar de protagonistas usufruindo seu estatuto de sujeito de direitos. Em suma, a "criança pensada a partir da positividade das suas próprias características” (SARMENTO, 2016, p. 8).

As crianças, a partir do novo conceito de socialização inaugurado pela Sociologia da Infância, têm totais condições de exercer sua participação ativa nas pesquisas. Dessa forma, elas passam a ser autores de suas próprias histórias, não precisando mais que os adultos desempenhem esse papel falando sobre ou por elas. "As crianças são competentes e têm capacidade de formularem interpretações da sociedade, dos outros e também, de si próprios, da natureza, dos pensamentos e dos sentimentos, de o fazerem de modo distinto e de usarem para lidar com tudo que as rodeia" (SARMENTO, 2005, p. 377).

Nessa perspectiva, a Sociologia da Infância, ao compreender a criança como ator social e assumir seu estatuto de sujeito de direito, defende a competência da criança para interpretar os seus mundos de vida, os quais são reveladores de suas realidades sociais, portanto, considera:

\footnotetext{
[...] as metodologias participativas com crianças como um recurso metodológico importante, no sentido de atribuir aos mais jovens o estatuto de sujeitos de conhecimento, e não de simples objeto, instituindo formas colaborativas de construção do conhecimento nas ciências sociais que se articulam com modos de produção do saber empenhados na transformação social e na extensão dos direitos sociais (SOARES; SARMENTO; TOMÁS, 2005, p. 54).
}

Embora destacada pelos autores como uma metodologia importante no processo de pesquisa com crianças, esta não se mostra uma tarefa fácil, pois ao desenvolvermos pesquisas com as crianças, colocando-as como participantes no trabalho, diversos cuidados precisam ser levados em conta. Faz-se necessário conhecer e respeitar as suas realidades, as suas características e as suas limitações. 
Há ainda que procurar, como pesquisador, ser aceito pelas crianças e pelo seu mundo, diminuindo a representação de autoridade e poder que os adultos representam às crianças, os quais são ocasionados pelas suas características físicas e pelo poder historicamente representado pela figura adulta. Cabe ao pesquisador, primeiramente, estabelecer um vínculo com os sujeitos pesquisados, a fim de, no momento da pesquisa, as crianças se sentirem confiantes e seguras com a presença e a escuta do pesquisador (CORSARO, 2011).

Ao pesquisar com as crianças, é preciso ainda ter ciência de que em primeiro lugar estará o bem-estar das mesmas e assim como em todo trabalho investigativo, imprevistos poderão acontecer, daí a importância e a seriedade que uma pesquisa com crianças precisa ser desenvolvida. A partir desses pressupostos se insere a problemática subjacente a este texto, que procura refletir sobre qual o lugar da criança na pesquisa, as questões teórico-metodológicas envolvidas e que cuidados éticos são necessários no desenvolvimento da investigação. Para tanto, o texto se organiza em duas seções, a primeira reflete sobre o ser criança, traçando uma linha de tempo do percurso histórico marcado por um estatuto secundarizado para chegar a sujeito de direitos. A segunda seção discute questões teórico-metodológicas e éticas da investigação com crianças.

\section{O ser criança: de um estatuto secundarizado a sujeito de direitos}

O reconhecimento da criança como sujeito de direitos por adultos da sociedade ocidental tem uma longa trajetória histórica, que passa pelas instituições sociais e, entre elas, as jurídicas e acadêmicas. Nesse percurso, a criança passou por períodos de invisibilidade, de práticas de infanticídio e abandono, de um estatuto subalternizado a uma sociedade adultocêntrica, percebida como homúnculo, para finalmente, em períodos mais recentes, ser vista como ser do presente, que faz parte da sociedade e tem direito a participar dela.

Para Rosemberg e Mariano (2010, p. 644):

[...] dentre os marcos fundantes desse reconhecimento destacam-se a Declaração Universal dos Direitos da Criança promulgada pela Organização da Nações Unidas - ONU -, em 1959, e a publicação do livro de Philippe Ariès (1961), L'enfant et la vie familiale sous l'ancien régime. Apesar de críticas que lhes foram feitas, ambos os textos instalaram discursos e práticas sobre a infância e as crianças contemporâneas.

As autoras ainda acrescentam que Ariés (1961), ao compreender a infância como uma construção social, constituindo-se no contexto social e discurso intelectual, insere as bases para a mudança de paradigma vigente, a partir das décadas de 1980 e 1990. Essa nova concepção de infância alçada à legítima condição de objeto das Ciências Humanas e Sociais rompe com o modelo desenvolvimentista da Psicologia, ataca o conceito de socialização passiva predominante até então na Antropologia, Psicologia e Sociologia e confere a criança o estatuto de sujeito, ator social (ROSEMBERG; MARIANO, 2010).

A nova compreensão de infância e criança provoca rupturas na produção teórica, discursos e práticas então vigentes, levando à construção de novos conceitos e reflexões que permitem a entrada da infância na esfera pública, ocupando uma posição importante na 
pauta de negociações das políticas públicas, inclusive nos marcos legais nacionais e internacionais como a Convenção Internacional sobre os Direitos da Criança de 1989.

A ideia de defesa dos direitos da criança apresenta um percurso com marcos fundamentais ressaltados por Rosemberg e Mariano (2010). Resgatam-se esses marcos para traçar uma linha de tempo, destacando-os pela sua importância histórica, política e social.

Em 1913, surge um primeiro esboço de um projeto de uma associação internacional de proteção à infância que contava com a participação de 37 Estados, mas interrompido devido à Primeira Guerra Mundial. Em 1919, é criado o Comitê de Proteção à Infância, pela Sociedade das Nações, que questionava o poder dos Estados sobre as crianças. Em 1921, foi constituída a Associação Internacional para a Proteção à Infância. Nessa linha do tempo destaca-se 1923, como um dos marcos mais importantes, pois Eglantine Jebb (18761928, reformista social britânica) iniciou o movimento internacional de defesa dos direitos da criança - The International Save the Children Union (Genebra,1920). Eglantine foi a responsável pela redação da Ata sobre os Direitos da Criança, na qual resumia os direitos de sobrevivência da criança em cinco pontos, documento que, no ano seguinte, foi adotado pela Liga das Nações, convertendo-se na Declaração dos Direitos da Criança, conhecida como a Declaração de Genebra. Esses cinco princípios foram, em 1937, reformulados para sete devido ao contexto pós Primeira Guerra Mundial.

Em 1934, a Sociedade das Nações aprova a Carta de Genebra e, em 1946, o Conselho Econômico e Social das Nações Unidas recomenda a adoção da Carta de Genebra. Após o término da Segunda Guerra Mundial, surge um movimento internacional a favor da criação do Fundo Internacional de Emergência das Nações Unidas para a Infância - UNICEF. Em 1948, é aprovada pelas Nações Unidas a Declaração Universal dos Direitos Humanos que contempla crianças e adolescentes.

O ano de 1959 marca de forma inovadora a Declaração dos Direitos Humanos ao incluir o direito de brincar e a desenvolver-se numa atmosfera de paz e amizade, trazendo também a ideia da criança como sujeito do direito internacional e como sujeito de direitos civis, uma vez que é por meio desse documento que, pela primeira vez, é afirmado que as crianças têm direito a um nome e a uma nacionalidade.

Vinte anos depois, em 1979, comemora-se o Ano Internacional da Criança. O governo polaco propõe às Nações Unidas a criação de um grupo de trabalho para elaborar um novo tratado de direitos humanos para as crianças. A tramitação do documento levou dez anos, pois, devido a ser um tratado de caráter mundial sobre os direitos da criança, os conflitos, divergências, interesses, acessos a recursos e poder diferentes, ele gerou um embate tenso e político entre os Estados que detinham também concepções diversas de criança e infância. O contexto da guerra fria também contribuiu para a complexidade das negociações entre as nações (ROSEMBERG; MARIANO, 2010).

A América Latina se fez presente principalmente por representantes do Brasil, Argentina, Peru, Venezuela e Cuba, quee tiveram uma participação discreta, mas constante, principalmente no movimento de "oposição às disposições sobre a adoção internacional proposta pelos países ocidentais industrializados, aliando-se, nessa questão, aos representantes dos países islâmicos, contrários à adoção por motivos religiosos" (ROSEMBERG;MARIANO, 2010, p. 709). 
Finalmente, em 1989 foi adotada pelas Nações Unidas a Convenção Internacional dos Direitos da Criança. ${ }^{1}$ Cento e noventa e três países ratificaram a Convenção, inclusive o Brasil, em 1990. Somente os EUA e a Somália se negaram a ratificar. ${ }^{2}$ Os países signatários indicaram especialistas independentes para compor um Comitê que avalia periodicamente a aplicação da Convenção, a partir de relatórios enviados pelos países. Até 2004, segundo Rosemberg e Mariano (2010, p. 710), com base no relatório da Fundación Bernard van Leer (2007), "haviam sido realizados debates gerais sobre os temas: exploração econômica da criança; direitos da criança e papel da família; direitos da menina; administração da justiça juvenil; direitos das crianças com necessidades especiais; HIV/Aids e o direito das crianças; violência contra a criança; realização dos direitos da criança na primeira infância".

De acordo, ainda, com Rosemberg e Mariano (2010, p. 711):

O Brasil apresentou seu primeiro relatório ${ }^{3}$ ao Comitê de Direitos da Criança da ONU em 2003, A Associação Nacional dos Centros de Defesa dos Direitos da Criança e do Adolescente - Anced - e o Fórum Nacional dos Direitos da Criança e do Adolescente apresentaram, na ocasião, um Relatório Alternativo da sociedade civil sobre Direitos da Criança no Brasil. O Comitê de Direitos da Criança apresentou 76 recomendações, sendo uma delas a de que o Brasil entregasse o próximo relatório até outubro de 2007. Não há informações oficiais até o momento, porém, a Anced elaborou, em março de 2009, em caráter preliminar, o 2.o_Relatório Alternativo dos Direitos da Criança.

A Convenção tem caráter mandatário, apresenta maior número de artigos em relação à Declaração de 1959, são 54, e contempla os direitos civis e políticos; econômicos, sociais e culturais; direitos especiais, ou seja: a Convenção também é conhecida pelos três "P": direitos de provisão (direitos básicos: saúde, educação, vida familiar, lazer, cultura, segurança); proteção (discriminação, injustiça, abuso sexual, violência, exploração, conflito) e participação (ser consultada, ouvida, acesso à informação, liberdade de expressão, opinião, a tomar decisões em seu interesse e benefício).

$\mathrm{Na}$ América Latina, a aprovação e difusão da Convenção coincidiu com o retorno da democracia em muitos países, possibilitando assim o ajuste de uma linguagem progressista dos novos direitos da criança à reconstrução democrática, o que os levou a transformar em lei nacional. No Brasil, temos a Constituição Brasileira de 1988 e o ECA - Estatuto da Criança e do Adolescente, promulgado em 1990, que reconhecem e asseguram os direitos da criança.

1 As informações contidas na linha do tempo traçada acima decorrem de anotações de aula no dia 21-10-2017 da Prof ${ }^{a}$. Dr ${ }^{a}$. Natália Fernandes, na disciplina de Direitos da Criança e Políticas Públicas, Instituto de Educação, Universidade do Minho.

2 A Somália enfrenta problemas referentes à sua própria constituição como Estado nacional. Um dos principais motivos pelo qual os EUA apenas assinaram a Convenção, mas não ratificaram, decorre do teor do art. $37^{\circ}$. alínea a, referente à proibição da cominação de pena de morte e prisão perpétua a menores de 18 anos de idade, o que se revelava incompatível com o direito interno norte-americano (ROSEMBERG; MARIANO, 2010, p. 710).

3 No Brasil, a elaboração do Relatório ao Comitê dos Direitos da Criança está a cargo da Subsecretaria de Promoção dos Direitos da Criança e do Adolescente - SPDCA -, órgão que substituiu o Departamento da Criança e do Adolescente - DCA (ROSEMBERG; MARIANO, 2010, p. 711). 
Fernandes (2009) afirma que o conceito de direito é complexo, estando sua história ligada à razão, sendo um conceito atribuído exclusivamente a indivíduos capazes de pensamento racional (homens), sendo negado a outros grupos (mulheres, crianças) que são mais guiados pelas emoções. A autora, ancorada em Alderson (2000), sustenta a ideia de que o conceito de direito também se relaciona com as necessidades "uma vez que uma base puramente racional de alocação de direitos é irrealista, pois a experiência demonstra que não é a razão por si só que conduz o pensamento e a ação; as ações humanas de prazer, dor, desejo, frustração e outras relacionam-se com as necessidades" (2009, p. 27).

A autora ainda acrescenta que a ideia de direitos vai de encontro a necessidades físicas e sociais, e muitas vezes podem sublinhar uma imagem assistencialista da infância, objeto de intervenções sociais de natureza caritativa, remediativa com ausência do Estado no que se refere a uma responsabilização pelas respostas às questões sociais.

Fernandes (2009) chama a atenção em seu estudo para a questão "direitos e necessidades", muitas vezes confundidos nas análises políticas e práticas sociais para a infância, destacando que as perspectivas com enfoque nos direitos da criança "sublinham uma imagem diferente de infância, na qual há uma responsabilização política e moral, no sentido de assegurar a sua aplicação". Ressalta ainda "a ação da criança como estratégia de realização de tais direitos, bem como, a aprovação de valores como igualdade e a universalidade no exercício dos mesmos" (2009, p. 28).

Para a autora, na intervenção social o que distingue uma abordagem centrada nas necessidades e outra pautada nos direitos é a exigência relativa à prestação de contas de cada uma delas. Para a primeira, não há prestação de contas e sim um comprometimento moral. Para a segunda, há obrigações morais e legais, ou seja, as intervenções sociais se baseiam no respeito e salvaguarda de seus direitos, implicando responsabilidade social e política dos parceiros sociais inseridos (FERNANDES, 2009).

Indo além dessa diferenciação, Fernandes propõe pensar os direitos da criança, compreendendo-os entre direitos sociais e direitos políticos. Os direitos sociais vinculam-se às necessidades de bem-estar e proteção (educação, saúde e proteção). E os direitos políticos se referem à participação da criança na tomada de decisão sobre os assuntos que lhe dizem respeito.

$\mathrm{Na}$ contemporaneidade, o termo "direitos" continua sendo um conceito ambíguo e contestado, surgindo então questões complexas relacionadas ao seu alcance, como: onde começam e terminam os direitos da criança. E como ficam os conflitos na relação crianças e adultos. As crianças são dependentes da ação de terceiros, geralmente, dos adultos que estabelecem relações de autoridade e poder. Dessa forma, o reconhecimento dos direitos da criança coloca em dúvida a tutela e o poder do adulto.

A polêmica em torno do debate dos direitos da criança é muito presente na sociedade e meio acadêmico, existindo um movimento social e científico que intenta promover a imagem de infância que reconhece as especificidades desse grupo social enquanto criança ator social (FERNANDES, 2009).

Porém, os contextos e as condições para que os direitos da criança sejam respeitados são muito diversos. A desigualdade social ampliou-se enormemente nas últimas décadas, há guerras obrigando crianças a fugirem, deixando suas casas e cidades, crianças morrendo 
de fome em seus países e ou afogadas nas praias do Mediterrâneo, trazendo uma imagem do horror representada pela mídia (SARMENTO, 2016). Essa imagem midiatizada mostra uma realidade social cruel de desagregação da própria sociedade como consequência dos conflitos e crises do capitalismo financeiro e que atinge a população de modo geral e, particularmente, as crianças.

Esse é o cenário atual em que se insere o debate acerca dos direitos da criança, e, passados os anos, a Convenção dos Direitos da Criança revela a sua incompletude e concretização paradoxal. Constitui uma base de trabalho que desafia continuamente a relação entre a lei escrita e a prática, mostrando-se uma lei de papel, bem como, a relação entre a norma universal e a diversidade cultural, entre a vontade política e a capacidade de concretização. Muitas transformações ocorreram nas últimas décadas em nível mundial, como a globalização, a revolução das tecnologias, o aumento das desigualdades sociais, diferentes configurações familiares e novas relações de trabalho, que impactam as sociedades e vão exigir atenção e mudanças na agenda da Convenção dos Direitos da Criança.

Portanto, acredita-se serem coerentes as palavras de Michael Freeman (2009) citadas por Fernandes (2017) "é melhor ver a Convenção sobre os Direitos da Criança como o início e não como a última palavra sobre os direitos. [...] Muitos países consideram como suficientes os aspectos retóricos e simbólicos. [...] Mas a Convenção é um importante marco. Atuando contra ela, o mundo continua a desrespeitar as crianças".

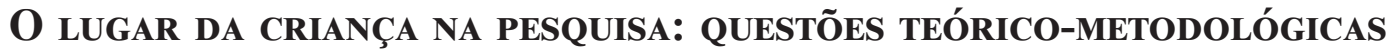 E ÉTICAS}

As pesquisas desenvolvidas sobre e com crianças no Brasil estão geralmente circunscritas aos programas de pós-graduação em nível de mestrado e doutorado na área da Educação, Psicologia, Saúde e outras afins. Em muitas dissertações e teses, o foco ainda é a instituição educativa, a organização curricular, as políticas públicas, a formação e práticas docentes e a criança nesse contexto permanece institucionalizada, secundarizada e silenciada.

Entretanto, esse panorama vem mudando, pois a pesquisa com crianças tem avançado de forma significativa na última década em relação à realidade luso-brasileira por meio de pesquisadores de diferentes áreas que buscam novas metodologias condizentes com os pressupostos dos estudos da criança (DORNELLES e FERNANDES, 2015).

Fazer pesquisa com a criança e não mais sobre a criança possibilita não só conhecer a criança, mas entender suas experiências sociais e culturais que ela compartilha com outras crianças e adultos, compreendendo como se dão essas relações e interações. Considera-se um passo adiante na busca do reconhecimento da criança como ator social (BUSS-SIMÃO, 2015).

Nessas pesquisas, a criança assume o papel de participante da investigação. É um espaço que vem sendo conquistado pela criança, pois o desenvolvimento do campo dos estudos da criança tem permitido, gradualmente, uma maior sensibilidade para escutar suas vozes e realizar estudos com as mesmas, aspirando a uma compreensão da condição humana a partir do ponto de vista da criança.

A interlocução da Sociologia da Infância com outras áreas de estudo tem possibilitado relações interdisciplinares, abrindo caminhos para novas compreensões das infâncias 
vividas pelas crianças a partir delas mesmas, como condição básica para dar conta das complexidades que se revestem seus mundos na contemporaneidade.

Nessa perspectiva, a Sociologia da Infância, ao entender as crianças como atores sociais plenos, competentes na formulação de interpretações sobre os seus mundos de vida e reveladores das realidades sociais, considera as metodologias participativas como um recurso metodológico importante para dar o estatuto de sujeito às crianças e não mais de mero objeto, possibilitando assim a construção de formas colaborativas na produção de conhecimento que direciona para a emancipação social e exercício do direito às crianças.

Compreender a criança como ator social participante, segundo Dornelles e Fernandes (2015), possibilita um novo realce à forma de entendimento da criança e sua posição nas ciências sociais, considerando-a como ator social, com voz e ação integrada no processo de investigação que participa em parceria com os adultos.

Esse se revela um novo paradigma para se pensar a emergência da participação infantil como uma questão social, política e científica. Na contemporaneidade, pensar a criança, a infância, leva a pensar num grupo social com um conjunto de direitos reconhecidos legalmente, entretanto, pouco efetivados na vida cotidiana, portanto, todo empenho para assegurar a participação é fundamental, já que a participação infantil é um instrumento de luta contra a exclusão. Para Dornelles e Fernandes (2015), a participação infantil é um princípio fundamental para assegurar o cumprimento dos direitos que as crianças possuem.

Contribuindo para a discussão, Tomás, (2007, p. 49) compreende que "participar significa influir diretamente nas decisões e no processo em que a negociação entre adultos e crianças é fundamental, um processo que possa integrar tanto as divergências como as convergências relativamente aos objetivos pretendidos e que resultam num processo híbrido".

Nessa perspectiva, a participação da criança na pesquisa, reconhecê-la como sujeito que pode falar em seu direito próprio, relatar visões e experiências válidas, pode resgatá-la do silêncio e da exclusão imposto como objeto passivo nas pesquisas tradicionais. A Convenção dos Direitos da Criança, em seu artigo 12, prescreve que a criança, de acordo com seu desenvolvimento etário, é capaz de emitir opiniões, sendo resguardado o direito de o fazer de forma livre, sendo também assegurado o direito de ser ouvida nos assuntos que lhe dizem respeito e de forma séria (SOARES; SARMENTO; TOMÁS, 2005).

Fernandes e Dornelles (2015, p. 67), com base em Qvortrup, Corsaro e Honig (2009), destacam esse entendimento afirmando que:

[...] os estudos da criança não negam, claro, que as crianças são pessoas pequenas, mas este fato não as torna menos humanas. Como referem, por vezes, fica-se com a impressão que a sua pequenez nos conduz a, conceptualmente, as encarcerar num micromundo ou num mundo de particularismos. É a exigência de ir para além destes micromundos e particularismos que nos move, quando defendemos modos de fazer pesquisa com crianças que as respeitem como sujeitos ativos, sendo para tal fundamental mobilizar a sua participação, mais ou menos implicada, nos processos de pesquisa.

Portanto, a partir desse respaldo legal se entende que as crianças têm direitos e competências para serem escutados e participarem de decisões que lhes afetam, assim, as me- 
todologias participativas são indicadas, pois pressupõem o reconhecimento prático desses direitos no domínio da pesquisa.

Segundo Soares, Sarmento e Tomás $(2005$, p. 55) “[...] o que se recupera com as metodologias participativas é a presença da criança-parceira no trabalho interpretativo, mobilizando para tal um discurso polifónico e cromático, que resulta da voz e acção da criança em todo o processo".

Para Soares (2006), a investigação participativa é um processo de participação social que se fundamenta num equilíbrio mutuamente possível de autonomia, cooperação e hierarquia entre as pessoas em que a tomada de decisão é partilhada com todos os envolvidos na investigação. A autora ainda afirma que:

Epistemologicamente, defende uma relação participada entre investigador e
investigado, onde, o investigado é também um investigador, estabelecendo-se
entre os dois uma relação interactiva e aberta à mudança.
Metodologicamente, a investigação é considerada como um espaço intersubjec-
tivo, para onde confluem múltiplas formas práticas, conceptuais, imaginárias e
empáticas de conhecimento, através de processos partilhados de produção de
conhecimento, entre investigadores e investigados.
É também, um processo de investigação densamente trespassado de significa-
dos e valores, em todas as etapas do seu percurso, o que se apresenta como um
desafio complexo na investigação com crianças, na medida em que, os signifi-
cados e valores que estão aí presentes, terão sempre uma dupla interpretação: a
dos adultos e a das crianças (SOARES, 2006, p. 29).

Segundo Tomás (2007, p. 47), "do ponto de vista metodológico, a investigação participativa procura métodos e técnicas que permitam conhecer transformando". A autora ainda complementa "investigação participativa é um paradigma emergente das Ciências Sociais críticas, um movimento político e um processo múltiplo de investigação, educação e acção".

A pesquisa participativa com crianças possibilita um avanço na construção da cidadania infantil. Revela-se um espaço político, de presença e ação, sendo parte do processo de desenvolvimento da investigação. Em termos metodológicos, a pesquisa com crianças deve mostrar um desenho flexível, aberto a novas possibilidades que se revelam à medida que a investigação avança.

Para Dornelles e Fernandes (2015, p. 70),

[...] é importante investirmos em metodologias que nos permitam atentar para a possibilidade de inventarmos novos territórios, novos questionamentos, novos caminhos investigativos com crianças. Para estarmos com elas, dando visibilidade aos seus ditos, duvidando de nossas verdades sobre o até aqui pesquisado acerca das infâncias e das crianças, colocando essas verdades em suspenso, quando se trata de investirmos nas investigações com crianças.

Em uma investigação que contemple a participação das crianças, as questões ético-metodológicas que as desenham não devem seguir um planejamento rígido, mas sim continuamente pensadas tendo em vista os sujeitos envolvidos, ou seja, as características das crianças, como: idade, gênero, vivências, contexto sociocultural. Esse critério também se 
estabelece em relação aos instrumentos para a coleta de dados. O diálogo deve ser mediador das interações entre sujeitos envolvidos na investigação.

Nessa perspectiva, Soares, Sarmento e Tomás (2005) propõem onze aspectos que se deve dar atenção ao planejar uma investigação com crianças que tenha a ética como princípio, a saber:

1. Valorização da voz e ação das crianças - é o indicador principal que baseará toda a investigação. A valorização dessa participação não permite processo de discriminação, exclusão e ou pseudoparticipação.

2. O consentimento informado - informar as crianças dos objetivos e dinâmica da investigação e obter seu consentimento é um dos momentos chave na pesquisa participativa.

3. Consideração de estratégias e recursos metodológicos plurais e criativos - escutar as vozes de todas as crianças sem distinção exige uma multiplicidade de recursos metodológicos.

4. A entrevista - ao ser utilizada na investigação participativa, deve assumir dimensões variadas (ex.: roda de conversa).

5. Observação participante - é válida em com outros instrumentos.

6. Registros escritos da criança - podem assumir vários formatos, diários, ensaios, observações, a depender do domínio da linguagem escrita pela criança.

7. Fotografias e vídeo - é uma alternativa ao registro escrito e possibilita à criança expressar suas representações de mundo.

8. Técnicas visuais - pode ser individual ou em grupo. Permite outros formatos de caracterização de contextos de vida.

9. Técnicas dramáticas, de role-play, observações de situações de faz de conta - permitem recuperar representações que podem ficar ocultas ao olhar do pesquisador.

10. A agência das crianças na avaliação do percurso da investigação - assim como no percurso da investigação se considerou a voz da criança, o mesmo deve ser feito no momento da avaliação.

11. A devolução da informação às crianças - é fundamental considerar a participação das crianças até o momento final de qualquer processo do qual fizeram parte.

A partir dos aspectos já citados se entende que o cuidado e atenção às questões ético-metodológicas devem permear toda a investigação, principalmente por se tratar de crianças, nesse sentido, o respeito à privacidade, seu consentimento ou recusa em participar da pesquisa, a liberdade de expressão das mesmas, a autonomia para emitir opiniões sem sofrer influências de outros, o respeito entre todos os participantes são pontos fundamentais para o bom desenvolvimento da investigação.

No Brasil, desde os anos de 1980, o debate sobre a questão da ética na pesquisa com crianças já se fazia presente nas publicações direcionadas aos pesquisadores. Segundo Barbosa (2014, p. 439), com base em Spinelli (2012), "nessas publicações eram abordados temas centrais como: consentimento informado, a coerção, as relações de poder entre adultos e crianças, os riscos, os benefícios, o retorno ou a devolução, o uso de imagens, a confidencialidade e os abusos". Como as crianças são consideradas pessoas vulneráveis, 
todas as pesquisas feitas com crianças necessitam aprovação prévia nos Comitês de Ética na Pesquisa (CEP). ${ }^{4}$

A regulamentação das pesquisas que envolvem seres humanos até a promulgação da Resolução n. 196-1996 não fazia referência à participação de crianças como sujeitos da pesquisa. É a partir dessa Resolução que se normatiza juridicamente essa participação, exigindo-se tomar por escrito o termo de consentimento do representante legal da criança e ou o consentimento da própria criança se ela tiver condições de compreensão.

Segundo Buss-Simão (2015), a Resolução n. 466-2012 define e traz uma distinção entre adultos e crianças, diferenciando os termos Consentimento Livre e Assentimento, sendo o primeiro um documento no qual é explicitado o consentimento livre e esclarecido do participante e ou responsável legal. Deve conter todas as informações em linguagem clara e objetiva sobre a pesquisa. Já o termo de Assentimento caracteriza-se como um documento destinado aos menores ou legalmente incapazes, escrito em linguagem acessível, que darão sua anuência após esclarecimentos sobre sua participação na pesquisa sem prejuízo do consentimento de seus representantes legais.

\section{CONSIDERAÇões FINAIS}

As ciências sociais não consideraram durante muito tempo o grupo geracional infantil como objeto de análise por pensar que as crianças não tinham capacidade de reflexão e ação. Esse fato distanciou a infância da investigação com crianças por não as considerar como unidade de investigação válida em si mesma ou como parceiras no processo de pesquisa.

A Sociologia da Infância contrapõe essa visão e reconhece a subjetividade da criança e a posiciona como ator social, sujeito da sua história e dos processos de socialização, considerando-a competente e capaz de atribuir sentidos e significados às próprias experiências. Portanto, a criança é participante ativa na sociedade, produz cultura por meio de suas relações com o mundo, com as pessoas que a rodeiam, com os lugares que frequenta e vivencia experiências.

A criança tornou-se visível socialmente e muitos são os estudos que abordam temas relacionados a ela e pesquisadores que se dedicam em investigar os diversos fenômenos que a envolvem. Conhecer a infância e a criança mostra-se uma tarefa complexa que envolve a interdisciplinaridade de campos científicos e um olhar atento e crítico às suas identidades, diversidades e contextos socioculturais.

Nas últimas décadas do século XX, internacionalmente, os direitos das crianças adquiriram uma nova dimensão. A partir da Convenção dos Direitos da Criança, em 1989, ratificada pela maioria dos países, se reconheceu os direitos civis, políticos e sociais das crianças. Entretanto, esses direitos, embora assegurados legalmente, concretamente no cotidiano das crianças ainda não se efetivaram plenamente. No entanto, a convenção sobre os Direitos das Crianças, assim como a legislação e demais instrumentos jurídicos que se

4 A Comissão Nacional de Ética na Pesquisa (CONEP) é uma comissão do Conselho Nacional de Saúde (CNS), criada pela Resolução 196/96, com a função de implementar as normas e diretrizes regulamentadoras de investigações envolvendo seres humanos, aprovadas pelo Conselho. Tem função consultiva, deliberativa, normativa e educativa, atuando com uma rede de Comitês de Ética em Pesquisa (CEP) organizados nas instituições onde as investigações se realizam. 
destinam às crianças, apesar de todas as limitações e críticas, explicitam uma marca de cidadania e o reconhecimento de sua capacidade de participação.

A participação infantil é, portanto, na contemporaneidade, uma premissa inquestionável nos discursos científicos e políticos que são produzidos a respeito da infância. A Sociologia da Infância, ao considerar as crianças como atores sociais e como sujeitos de direitos, assume a questão da participação das crianças como central na definição de um estatuto social da infância e na caracterização do seu campo científico (SOARES; SARMENTO; TOMÁS, 2005).

Nessa perspectiva, conhecer a criança e adentrar seu mundo por meio da pesquisa participativa exige a criação de múltiplos olhares a respeito do contexto e sobre o modo como delineia suas ações. Implica a criação de estratégias metodológicas que lhe permitam diferentes modos de expressão e movimentos, sendo tarefa do pesquisador adulto tornar audíveis e visíveis as ações das crianças durante a investigação. A pesquisa e o desenho pelo qual é constituída deverão criar condições para que crianças e adultos possam, a partir de diferentes linguagens, visibilizar as ações e lhes dar sentido. Além das questões teórico-metodológicas, deve-se também ter muita atenção à ética em respeito à criança e cuidados com seu bem-estar.

Enfim, trata-se de considerar e dar à criança seu lugar como participante e parceira no processo de investigação, partilhando um espaço intersubjetivo e inter-relacional de forma concreta e ética.

\section{REFERÊNCIAS}

BELLONI, M. L. O que é sociologia da infância. Campinas-SP: Autores Associados, 2009.

BUSS-SIMÃO, M. Consentimento informado e assentimento: processos de obtenção de permissão das crianças pequenas em pesquisas. In: ANJOS, C. I. dos; FERREIRA, F. I. (Orgs.). Infância e Educação: olhares sobre o contexto e o cotidiano. Maceió: EDUFAL, 2015, p. 61-71.

CORSARO, W. A. Sociologia da infância. Porto Alegre: Artmed, 2011.

DORNELLES, L. V.; FERNANDES, N. Estudos da criança e pesquisa com crianças: nuances luso-brasileiras acerca dos desafios éticos e metodológicos. Currículo sem Fronteiras, v. 15, n. 1, p. 65-78, jan./abr. 2015.

FERNANDES, N. Infância, Direitos, Representações, Práticas e Poderes. Porto: Edições Afrontamento, 2009.

FORMOSINHO, J. O. O desenvolvimento profissional das educadoras da infância; entre os saberes, os afetos, entre a sala e o mundo. In: Machado, Maria Lucia de A. Encontros e desencontros em educação infantil, 3. ed. São Paulo: Cortez, 2008. 
ROSEMBERG, F.; MARIANO, C. L. S. A Convenção Internacional sobre os Direitos da Criança: debates e tensões. Cadernos de Pesquisa, v. 40, n.141, p. 693-728, set./dez. 2010.

SARMENTO, M. J. Gerações e alteridade: interrogações a partir da sociologia da infância. Revista Educação e Sociedade. Campinas, v. 26, n. 91, p. 361-378, mai./ago. 2005.

SARMENTO, M. J. Retrato em positivo - Entrevista com Manuel Jacinto Sarmento. In: FRIEDMANN, A.; ROMEU, G. (Orgs.). Quem está na escuta; Diálogos, reflexões e trocas de especialistas que dão vez e voz às crianças. São Paulo: Núcleo de Estudos e Pesquisas em Simbolismo, Infância e Desenvolvimento, 2016, p. 6-14.

SARMENTO, M. J.; FERNANDES, N.; TOMÁS, C. Políticas públicas e participação infantil. Educação, Sociedade e Culturas, n. 25, 2007, p. 183-206.

SOARES, N. F. A investigação participativa no grupo social da infância. Currículo sem Fronteiras, v. 6, n. 1, p. 25-40, jan./jun. 2006.

SOARES, N. F.; SARMENTO, M. J; TOMÁS, C. Investigação da infância e crianças como investigadoras: metodologias participativas dos mundos sociais das crianças. Nuances. UNESP - Presidente Prudente, v. 12, n. 13, p. 50-64, 2005.

TOMÁS, C. "Participação não tem idade" Participação das crianças e cidadania da infância. Contexto e Educação. Unijuí, Ano 22, n. 78, jul./dez. 2007.

\section{DADOS DA AUTORA:}

\section{Marta Regina Brostolin}

Pós-doutorado pela Universidade do Minho. Braga - Portugal. Professora no Programa de Pós-Graduação em Educação da Universidade Católica Dom Bosco. Campo Grande/MS Brasil.brosto@ucdb.br

Submetido em: 5-3-2019

Aceito em: $11-4-2020$ 